\title{
SATISFAÇÃO NO TRABALHO DOS GESTORES ESCOLARES
}

\author{
JOB SATISFACTION OF EDUCATIONAL MANAGERS
}

DOI: http://dx.doi.org/10.12712/rpca.v5i2.24

Vera Regina Ramos Pinto

Mestrado Profissional em Sistemas de Gestão

Universidade Federal Fluminense - UFF

verreg28@gmail.com

\section{Sandra R. H. Mariano}

Mestrado Profissional em Sistemas de Gestão

Universidade Federal Fluminense - UFF

sandramariano@empreendedorismo.uff.br

\section{RESUMO}

Este artigo apresenta a percepção de um grupo de gestores escolares sobre sua satisfação no trabalho. Foi realizada uma survey e selecionada uma amostra não probabilística composta por 105 gestores de escolas da Rede SESI/SENAI nacional e 46 gestores de escolas da rede pública com melhores desempenhos no estado do Rio de Janeiro segundo as avaliações do governo federal. Conclui-se que as variáveis que contribuem para o alto nível de satisfação com o trabalho percebido na Rede SESI/SENAI são: conhecimento do que fazer para atingir os objetivos da instituição; os impactos causados pelo trabalho do gestor na obtenção destes objetivos; e o prazer que o trabalho proporciona. Na Rede Pública, além do conhecimento dos impactos causados pelo trabalho no alcance dos objetivos da organização, observou-se também que o orgulho de trabalhar nas melhores escolas; o clima de camaradagem e o trabalho e equipe contribuem para aumentar os níveis de satisfação.

Palavras-chave: Satisfação no trabalho. Gestores de escolas. Rede pública. Rede SESI/SENAI.

\begin{abstract}
This article presents the perception from a group of educational managers about your job satisfaction. We conduct a survey and a non-probability sample was selected, composed of 105 school managers from SESI/SENAI national education system and 46 educational managers from public schools of Rio de Janeiro State with the best performing according to performance evaluation of the federal government. We concluded that the variables that contribute to the high level of job satisfaction to SESI/SENAI education system are: knowledge of what to do to achieve the goals of the institution, the impacts caused by the manager's work in obtaining these goals, and the pleasure that work provides. In the Public Schools, the knowledge of the impacts caused by work in reaching the goals of the organization, there was also proud to work in the best schools; the companionship and team work contribute to higher levels of job satisfaction.
\end{abstract}

Keywords: Job satisfaction. Educational managers. Public schools. SESI/SENAI Education System. 


\section{INTRODUÇÃO}

No Brasil, o tema da educação e os desafios para elevar a qualidade do ensino têm ocupado das manchetes dos jornais às agendas de pesquisadores na área de gestão e de educação. 0 envolvimento do Diretor da escola com a gestão escolar e a sua capacidade de administrar a equipe de professores e funcionários tem sido considerada essencial para que a escola cumpra o seu papel. J/ h| muitos anos, Darcy Ribeiro (1984, p.67) dizia que "a escola que alfabetizou o mundo consiste, essencialmente, em uma professora bem preparada, estimulada e provida de um mínimo de material did|tico para as crianças que não possam adquirir". Mas o que dizer da satisfação destes profissionais para com o seu trabalho? Será que a escola que alfabetiza os brasileiros tem profissionais satisfeitos com o próprio trabalho?

Em 2010, a Escola Municipal João de Deus, que obteve o melhor resultado de aprendizagem dos egressos, entre todas as instituições de ensino fundamental do estado Rio de Janeiro, incluídos os estabelecimentos públicos e particulares, alçando a nota 7,8 (sete vírgula oito) no Índice de Desenvolvimento da Educação Básica (IDEB), possui uma infraestrutura modesta, mas é gerida por uma Diretora que se diz satisfeita com o seu trabalho e também atribui o resultado alcançado pela escola à seriedade e à dedicação da equipe de treze professores: nas palavras da diretora Luciana Landrino "não h| m|gica. 0 que conseguimos é resultado de muito empenho" (REVISTA VEJA, 2010).

Portanto, melhorar a qualidade do ensino no Brasil está relacionado com a compreensão dos fatores que dão efetivo sentido ao trabalho do gestor da escola e também do professor, bem como os fatores que contribuem com a satisfação no exercício do trabalho.

Compreender o que pensa o gestor escolar sobre a natureza do seu trabalho é muito importante, pois, segundo Drucker (2002, p. 43), pode-se antecipar, com certa segurança, que "nos próximos cinquenta anos, as escolas e universidades mudarão cada vez mais radicalmente do que o fizeram desde que assumiram o atual formato há mais de 300 anos, quando se reorganizaram em torno do livro impresso". Dois fatores que se destacam na impulsão destas mudanças são a inserção de novas tecnologias de ensino-aprendizagem e as demandas de uma sociedade baseada no conhecimento, que exige cada vez mais alta performance, portanto, melhores desempenhos e resultados das escolas, posto que a educação é percebida como o principal vetor de desenvolvimento doindivíduo.

A exigência de melhores desempenhos, normalmente, recai sobre os gestores destas escolas. Por isso mesmo, os sujeitos desta investigação foram gestores de escolas públicas do estado do Rio de Janeiro (Rede Municipal e Rede Estadual) e gestores de escolas do Serviço Social da Indústria (Rede SESI) e do Serviço Nacional de Aprendizagem Industrial (Rede SENAI).

Assim, buscou-se responder algumas perguntas nesta pesquisa: Qual o nível de satisfação dos gestores escolares para com o seu trabalho? Quais são os fatores que afetam o nível de satisfação do gestor escolar? Há alguma diferença de nível de satisfação entre gestores da Rede SESI (escolas particulares) e da Rede Pública? Em outros termos, buscou-se compreender melhor quais são os fatores que contribuem para a maior ou menor satisfação do profissional no exercício do seu trabalho na administração escolar. 


\section{SATISFAÇÃO NO TRABALHO}

No contexto desta pesquisa, entende-se que compreender o que pensa o gestor escolar sobre a natureza do seu trabalho e o quanto este o satisfaz é uma das chaves para a construção de uma escola de qualidade, capaz de formar indivíduos que atendam às necessidades de crescimento do país. Por este motivo foi empreendida uma pesquisa sobre satisfação no trabalho junto a gestores de escolas públicas e particulares.

A preocupação com a satisfação no trabalho é um tema que vem ocupando gestores e acadêmicos da Administração há longo tempo. Sobre como Taylor e Fayol pensaram na satisfação no trabalho das pessoas, Hickson e Pugh (2004) destacam que para contrabalançar o efeito negativo do trabalho especializado, repetitivo e monótono, Taylor desenvolveu um sistema de pagamento por produtividade. Na época, acreditava que as pessoas só poderiam ser motivadas financeiramente (homem econômico) e, por isso mesmo, buscando a satisfação dos seus funcionários, instituiu o sistema de pagamento por produtividade. Fayol, ainda segundo Hickson e Pugh (2004), na mesma direção, acreditava que melhorando a remuneração do pessoal, especialmente dos gestores, obteria a justa e garantida satisfação dos empregados e, neste caso, a organização obteria os melhores desempenhos em retribuição. No caso de Fayol, o pressuposto era que a melhoria do padrão de desempenho das chefias de nível hierárquico superior significaria melhoria do desempenho dos outros níveis e, portanto, da organização como um todo.

Entre os neoclássicos, Urwick (1943), Gulick et al. (1937), não houve uma preocupação específica com a satisfação no trabalho dos gestores, tampouco dos operários. Seu objetivo era normatizar a gestão das empresas para compreendê-la. "Para eles, a essência da função gerencial era a obediência ao planejamento, organização, assessoramento, direção, coordenação, comunicação e orçamento (MAESTRO FILHO e DIAS).

Somente em meados da década de 1940 e início da década de 1950, vieram os estudos de Mayo (1947), Lewin (1935) e Roethlisberger (1941), cuja ênfase estava no fator humano. Seu objetivo era evitar a tendência à desumanização do trabalho decorrente da aplicação de métodos rigorosos e especialização do trabalho propostos, principalmente, por Taylor.

A partir deste período é que os trabalhadores começaram a ser considerados de modo mais humano, com vontades e objetivos próprios, além de serem vistos como sujeitos que fazem parte de determinado grupo e que necessitam da aprovação deste grupo que lhes provê sentido de pertença. Deu-se início, então, à defesa do mote que o fator humano é fundamental para a organização saudável, para que no final se torne ainda mais produtiva. A preocupação com a satisfação no trabalho começou a ocupar lugar de destaque entre os estudiosos do homem nas organizações.

Contemporaneamente vem se dando ênfase à ideia de que as organizações possuem também um capital humano, a saber: uma combinação de conhecimento, habilidades, capacidade de inovação e a capacidade de desenvolvimento de tarefas pelos empregados, ou seja, aborda a competência dos trabalhadores ou a capacidade deles para agirem em diversas situações (EDVINSSON e MALONE, 1998).

No contexto em que o trabalho torna-se cada vez mais intelectual e, portanto, menos passível de controles observáveis e mensuráveis, como o que ocorria no mundo do chão de fábrica no início do século XX, compreender a natureza dos processos que levam à satisfação no trabalho 
tem sido um grande desafio para as organizações. Ainda mais se considerarmos que as pessoas vêm sendo percebidas como uma importante fonte de vantagem competitiva.

De acordo com Bergamini, (1990, p. 51), o desafio est| em "como conseguir empregados mais produtivos e, particularmente, mais dóceis aos objetivos organizacionais". Archer (1990, p. 3), por sua vez, acredita que "a tarefa de induzir comportamento positivo deverá tornar-se mais fácil, caso o verdadeiro relacionamento entre motivação, satisfação e comportamento seja claramente compreendido". Segundo esse autor, h| uma falsa ideia "de que os motivadores e os fatores de satisfação sejam as mesmas coisas".

Na realidade, um motivador nada mais é que um motivo - uma necessidade, por definição. Por outro lado, um fator de satisfação é alguma coisa que satisfaz uma necessidade. [...] a motivação é definida como uma inclinação para a ação que tem origem em um motivo (necessidade) e a satisfação é o atendimento de uma necessidade ou sua eliminação. (ARCHER, 1990, p.4)

Para tornar mais claros os conceitos relacionados à motivação e satisfação, Archer (1990) assinala que a |gua, por exemplo, é um "fator de satisfação de uma necessidade denominada sede". A motivação é a sede e a |gua é o fator que satisfaz a necessidade. Neste caso, de nada adianta oferecer 10 litros de água a um indivíduo que não tem sede. Coda (1990, p. 88), na mesma direção de Archer (1990), é ainda mais contundente.

O salário é, frequentemente, apontado até como verdadeira motivação para o trabalho, principalmente quando examinada sua importância dentro do ambiente e contexto das empresas brasileiras. Mas, na realidade, o interesse por salário vem exclusivamente em função daquilo que este fator possibilita atender, e confundi-lo com motivação seria cometer o mesmo engano de dizer que, por exemplo, carne e pão motivam pessoas famintas.

É preciso lembrar apenas que a motivação está presente em cada comportamento dos sujeitos e, ao mesmo tempo, tem papel ativo no direcionamento do comportamento. São os fatores de satisfação ou de contrassatisfação que podem modificar os níveis de motivação resultando em um comportamento positivo (não frustrado) quando aumentam a satisfação, diminuindo a tensão da necessidade ou em um comportamento negativo (frustrado) quando diminuem a satisfação, aumentando a tensão da necessidade, respectivamente. Segundo Handy (1978), se pudéssemos compreender e, então, prever os modos como os indivíduos são motivados, poderíamos influenciá-los, alterando os componentes desse processo de motivação. 0 próprio autor questiona-se quanto a este processo ser um ato de "manipulação - ou de gerência". "Tal compreensão poderia, certamente, levar à obtenção de grande poder, uma vez que permitiria o controle do comportamento sem as armadilhas visíveis e impopulares do controle" (HANDY, 1978, p. 27).

0 que se observa é que o construto motivação pode ser entendido como um processo que alude à vontade do sujeito de realizar determinado trabalho ou de atingir um objetivo e que acena para, pelo menos, três aspectos: fazer um esforço, manter esse esforço até que o objetivo seja atingido e consagrar a ele a necessária energia. Em outras palavras, é muito mais fácil as pessoas dedicarem tempo às atividades para as quais são motivadas. Neste sentido, a motivação pode ser percebida, "em última an|lise, como uma questão de alocação de tempo". A motivação é, então, uma função interna a cada pessoa, uma força propulsora que tem suas fontes, frequentemente, no interior de cada um e cuja satisfação ou insatisfação fazem parte integrante de sentimentos que são tão-somente experimentados dentro de cada pessoa. 


\section{(LÉVY-LEBOYER apud BERGAMINI, 1990c, p. 46)}

Um dos modelos de motivação mais difundidos é o estudo desenvolvido por Maslow (1966) sobre a hierarquia de necessidades do indivíduo. Este modelo baseia-se no pressuposto de que existe uma hierarquia segundo a qual o indivíduo prioriza as suas necessidades.

As diferentes necessidades básicas estão mutuamente relacionadas numa ordem hierárquica, de tal modo que a satisfação de uma necessidade e sua consequente remoção do centro do palco provocam não um estado de repouso ou de apatia estóica, mas, antes, o aparecimento na consciência de outra necessidade mais alta; a carência e o desejo continuam, mas em nível superior. (MASLOW, 1966, p. 57)

Como se pode observar, satisfação e motivação são substantivos que se complementam e, via de regra, são encontrados juntos em artigos que tratam de um tema ou de outro. Para Maslow (1970, p. 104), por exemplo, uma necessidade satisfeita pode motivar um comportamento com objetivo de atender novas necessidades, uma vez que, "na realidade, a maioria das pessoas em nossa sociedade se encontra parcialmente insatisfeita em todas as suas necessidades humanas".

Herzberg (1962), outro grande estudioso do comportamento humano, também relacionou satisfação e motivação. Baseado em seus estudos sobre a teoria de dois fatores ou da higiene, Herzberg afirmava que em qualquer situação de trabalho poder-se-ia fazer a distinção entre os fatores que não satisfazem e os que satisfazem. 0 interessante é que esses fatores não se opõem. 0 fato de se tratar de fatores de insatisfação não os transforma em fatores de satisfação ou de motivação.

A Teoria dos Dois Fatores de Herzberg (1962) explica o comportamento das pessoas em situação de trabalho e mostra que existem dois fatores que orientam o comportamento das pessoas: os fatores higiênicos ou extrínsecos e os fatores motivacionais ou intrínsecos. Os primeiros dizem respeito ao ambiente e às condições de trabalho e estão fora do controle das pessoas. Os fatores higiênicos também são conhecidos como fatores insatisfacientes. Os segundos, por sua vez, estão relacionados ao conteúdo do cargo e à natureza das tarefas que o indivíduo executa. Isto significa, pelo menos para Herzberg (1973), que os fatores motivacionais estão sob o controle das pessoas, haja vista que estão relacionados com aquilo que elas fazem. Os fatores motivacionais também são denominados fatores satisfacientes.

Nos estudos de Herzberg (1968, p. 72 e 74) são considerados fatores de motivação (de satisfação): realização; reconhecimento; trabalho em si; responsabilidade; e, promoção. Nos fatores de higiene (de insatisfação) encontram-se: política e administração da organização; supervisão; condições de trabalho; relações interpessoais (com os superiores, os subordinados e os colegas); e, salário. Os fatores higiênicos são profiláticos e preventivos, pois apenas evitam a insatisfação, ou seja, não geram satisfação no trabalhador. Os fatores motivacionais, por outro lado, podem ter um efeito de desmotivação, provocando a apatia do trabalhador, inclusive causando desinteresse e falta de sentido no trabalho já que organização é meramente um lugar para trabalhar. Em outros termos, quando os fatores motivacionais são ótimos, eles provocam a satisfação nas pessoas e quando são ruins ou precários, evitam a satisfação.

Os estudos de Herzberg contribuem para a afirmação feita por Handy (1978, p. 28) de que "h| pouca evidência no sentido de que o trabalhador satisfeito realmente trabalhe mais. Todavia, 
há forte apoio para a sugestão de que um trabalhador satisfeito tende a permanecer na mesma organização".

Montana e Charnov (1998) comparam a Teoria dos Dois Fatores de Herzberg com a Teoria da Hierarquia das Necessidades de Maslow. Esses autores destacam que os fatores motivacionais de Herzberg podem ser comparados com as necessidades dos níveis superiores identificadas por Maslow que serviam para motivar o desempenho do trabalho. As necessidades dos níveis inferiores, ou básicos, que agem como fatores de manutenção, possivelmente de insatisfação, e, por último, a necessidade de pertencer, que deveria funcionar como um fator motivador ou de insatisfação.

McGregor (1973), a posteriori, fazendo uma análise crítica da administração, contribuiu para uma melhor compreensão acerca da motivação e elaborou uma nova abordagem para a administração das organizações. Utilizando-se de premissas e proposições a respeito do homem na organização, McGregor propôs duas teorias. A chamada Teoria X (McGregor, 1970) que se baseia nas convicções pouco explícitas, mas bastante difundidas, de que: o homem médio trabalha o mínimo possível; não gosta de responsabilidade, prefere ser dirigido. Sendo que, no âmbito da administração convencional, as implicações são: a administração é responsável pela organização dos elementos produtivos da empresa - dinheiro, materiais, equipamento, pessoal - para a realização de fins econômicos. E, no que diz respeito às pessoas, especificamente, esse é um processo de dirigir seus esforços, motivando-as, controlando suas ações, modificando seu comportamento, tendo-se em vista as necessidades da organização. As pessoas devem, portanto, ser persuadidas, recompensadas, punidas, controladas. A tarefa da administração resume-se a controlar os administradores subordinados ou os funcionários.

Segundo o próprio McGregor (1973, p. 11), talvez a melhor maneira de mostrar porque a abordagem convencional da administração seja inadequada para examinar o problema da motivação, concordando com Maslow, é afirmar que "o homem é um animal de contínuos desejos - logo que satisfaz uma de suas necessidades, aparece outra em seu lugar. Esse processo é intermin|vel. Vai do nascimento até a morte".

A menos que haja oportunidades no trabalho para satisfazer as necessidades mais elevadas, o pessoal sentirá privação e seu comportamento irá refletir essa privação. Sob tais condições se a administração continuar a focalizar nas necessidades fisiológicas, seus esforços se tornarão ineficazes. 0 pessoal irá apresentar pedidos insistentes de maiores salários. Apesar do dinheiro ter apenas um valor limitado na satisfação de muitas das necessidades de nível mais elevado, poderá se tornar o foco de interesse se for o único meio disponível. (McGREGOR, 1973, p. 15)

Para McGregor (1973), a administração realizada apenas através de direção e controle não funciona para fornecer motivação eficiente para o esforço humano atingir os objetivos da organização. "Falha porque a direção e o controle constituem métodos inúteis para motivar pessoas cujas necessidades fisiológicas e de segurança são razoavelmente satisfeitas e cujas necessidades sociais, egoísticas e de autorrealização são predominantes" (McGREGOR, 1973, p. 17). $O$ autor propõe, então, uma nova teoria da administração que ele chama de Teoria Y: as pessoas não são passivas ou resistentes às necessidades da organização por natureza. Ficaram assim como resultado da experiência em outras organizações. Nessa abordagem, "a administração é considerada, precisamente, um processo de criação de oportunidades de realização de potenciais, de remoção de obstáculos, de encorajamento de crescimento, de 
provimento de liderança" (McGREGOR, 1973, p. 18).

Para Hampton (1973), McGregor resume duas estratégias de administração diferentes, em suas suposições, relaciona essas estratégias com resultados organizacionais, contesta alguns fundamentos comuns ao pensamento empresarial, abrindo novas e animadoras possibilidades. A satisfação no trabalho, neste caso, poderia ser compreendida como "um estado de prazer emocional resultante da avaliação que um profissional faz sobre até que ponto seu trabalho apresenta a capacidade de facilitar ou permitir o atendimento de seus objetivos e valores" (LOCKE apud CODA, 1990, p. 88). De acordo com Coda (1990, p. 89).

A satisfação no trabalho pode ser mensurada em relação a uma série de fatores, sendo aqui ressaltados dois considerados básicos. 0 primeiro diz respeito à satisfação em relação ao conteúdo e tipo do trabalho que está sendo realizado e o segundo fator é representado pela satisfação dos funcionários de uma organização com relação às políticas de recursos humanos definidas e que servem de guia para a gestão destes funcionários.

Satisfação no trabalho para Montana e Charnov (1998, p. 203), portanto, é "a atitude e o sentimento no geral que um indivíduo tem sobre seu trabalho". Kouzes e Posner (1991, p. 43), inclusive, afirmam que

se o trabalho chegar a ser visto somente como uma fonte de dinheiro e nunca como fonte de satisfação, então os empregados irão ignorar totalmente outras necessidades humanas no trabalho, tais como aprendizado, autovalor, orgulho, competência. Os empregados irão considerar o prazer profissional de suas tarefas totalmente irrelevante e estruturarão o trabalho de forma estritamente utilitária. Os resultados serão - na verdade, já foram desastrosos para muitas organizações. Empregando somente as mãos dos trabalhadores, e não suas cabeças e seus corações, as organizações perdem um precioso retorno sobre seus investimentos em pessoal.

Kouzes e Posner (1991) também acreditam que, se os trabalhadores tiverem que justificar seu emprego exclusivamente em termos econômicos, nunca irão contribuir com algo mais que o mínimo, haja vista que também se sentirão alienados e sairão da organização quando surgir outro trabalho com melhor remuneração, ainda que mínima.

Bowditch e Buono (1992), estudando o comportamento organizacional e a satisfação dos trabalhadores, relacionaram a qualidade de vida no trabalho (QVT) com a existência de condições e práticas organizacionais, bem como com os efeitos visíveis que as condições de trabalho têm no bem-estar das pessoas. Na mesma direção, Werther e Davis (1983, p. 71) constataram que os esforços para melhorar a QVT, na verdade, procuram tornar os cargos mais produtivos e satisfatórios e perceberam que a mesma é afetada por fatores, tais como: supervisão, condições de trabalho, benefícios, pagamento e projeto de cargo, fatores também relacionados à satisfação do indivíduo para com o seu trabalho. Rodrigues (1994) acredita que a QVT deve atender tanto às necessidades da organização quanto do trabalhador. Isto é, tem a ver com produtividade, mas também com a relação de satisfação entre o indivíduo e a organização na qual trabalha. Conforme Timossi et al. (2010, p. 2) ainda é possível perceber,

de forma generalizada, que a investigação da QVT tem se preocupado principalmente com a satisfação do colaborador em relação a inúmeros fatores, como: salário; segurança; saúde no trabalho; condições físicas de trabalho que reduzam ao mínimo o risco de doenças ocupacionais e acidentes 
de trabalho; desenvolvimento das capacidades e múltiplas habilidades; autonomia; informação; crescimento profissional; integração social, e espaço de vida no trabalho e fora dele.

A saber, segundo Ulrich (2000, p. 155), “o local de trabalho está se tornando o meio primário de satisfação pessoal". Assim, para o indivíduo conseguir sobreviver e se autorrealizar, via de regra, começará por oferecer seu trabalho ao mercado, buscando pertencer a uma organização como membro colaborador, gerando valores econômicos para esta. Obviamente, há a contrapartida organizacional.

Para que se alcance o grau de satisfação dos colaboradores, é preciso que a QVT encontre maneiras de atingir o bem estar como: a renda deverá ser compatível com o mercado e que de algum modo proporcione condições de suprir necessidades básicas e sociais; tenha orgulho de fazer parte da empresa; estimular a autoestima, mostrando como é importante a sua colaboração na organização; ter uma definição positiva da empresa perante a sociedade; proporcionar uma relação equilibrada entre tempo de trabalho e lazer com a sua família; estabelecer horários acessíveis e formas de labor sensatas; oferecer oportunidades de cargos por merecimento, dedicação, competências; utilizar o potencial que o colaborar detém; respeitar os direitos legais e ser justo nas recompensas merecidas. (KARPINSKI e STEFANO, 2008, p. 4)

Enfim, a satisfação do indivíduo no trabalho está relacionada a diversos fatores organizacionais considerando seu ambiente externo e interno. Nesse contexto, não é possível deixar de mencionar a Experiência de Hawthorne, realizada por Mayo e colaboradores, que mostrou que apenas a recompensa salarial, mesmo quando generosa, não é o único fator decisivo para a satisfação do trabalhador. Isto é, o homem é motivado, não apenas por estímulos econômicos, mas também por recompensas sociais, simbólicas e não materiais. Já naquele período, as principais conclusões de Mayo (1938) indicavam que o mundo social de uma pessoa adulta se dá em relação à sua atividade no trabalho. Conclusões, ainda hoje, válidas e coerentes, mesmo tendo o mundo do trabalho passado por diversas transformações.

Enfim, das poucas pesquisas realizadas junto aos profissionais da educação, abordando a satisfação no trabalho, destaca-se o artigo de De Cooman et al. (2007, p.124) onde se assinala que em muitos países ocidentais, a falta de professores tem sido debatida, pois os professor estão envelhecendo ao mesmo tempo em que os novos graduandos, que poderiam entrar ou que estão cursando licenciatura, não necessariamente vêem o ensino como uma carreira promissora, o que resulta em mais indivíduos que abandonam a profissão a cada ano.

Esses autores comparam dois grupos de indivíduos que concluíram licenciatura: um grupo que trabalha na área de ensino e outro que não está na área educacional, e explora a motivação para buscar um trabalho de ensino com base em motivos e valores de trabalho. A partir da resposta de 241 professores formados recentemente, concluíram que os professores consideram as características intrínsecas, altruísticas e interpessoais como fortes motivadores específicos de trabalho. Além disso, os professores preferem valores interpessoais e altruístas relacionados ao trabalho, enquanto os não-docentes são mais atraídos por valores individualistas de trabalho, tais como oportunidades de carreira e posições de poder.

Na mesma época, um estudo realizado no Reino Unido (CROSSMAN e HARRIS,

2007) 
examinou a satisfação do trabalho de professores do ensino médio em diferentes tipos de escola, tendo em vista que a baixa satisfação no trabalho tem sido citada como uma possível causa da crise atual no ensino naquele país. Os professores das escolas independentes e com gerenciamento privado mostraram maior satisfação no trabalho enquanto que, em escolas administradas por fundações religiosas e de outros tipos, a satisfação dos professores foi menor. 0 estudo não apontou diferenças significativas na satisfação do trabalho quando analisados a idade, o gênero ou o tempo de serviço do professor.

\section{METODOLOGIA DA PESQUISA}

Para responder aos objetivos propostos foi realizada uma pesquisa de campo quantitativodescritiva, na qual podem ser estabelecidas relações entre variáveis (TRIPODI et al., 1975). De acordo com Malhotra (2001), a pesquisa descritiva tem como principal objetivo a descrição de determinado fenômeno. Através da pesquisa descritiva é possível examinar relações entre os fatos e ocorrências observados, bem como trabalhar com amostras representativas da população em estudo. Este tipo de pesquisa também permite a análise quantitativa dos dados, pois uma das características mais significativas deste tipo de pesquisa é a utilização de técnicas padronizadas de coleta de dados através de questionários.

Hair Jr. et al. (2005) ainda destacam que os estudos descritivos podem propiciar ao pesquisador um panorama ou uma descrição dos elementos em um determinado momento, uma vez que os dados são coletados em um ponto único no tempo e processados estatisticamente. 0 uso de questionário neste tipo de pesquisa, segundo Hair Jr. et al. (2005, p. 104), pode oferecer dados quantitativos que são mais objetivos, uma vez que os resultados estatísticos não dependem apenas da opinião do pesquisador. Embora sejam fundamentados nas habilidades do pesquisador como analista.

Os estudos descritivos em geral envolvem as atividades de criação de dispositivos para a coleta de dados, verificação de erros, codificação dos dados e armazenamento dos dados, conforme se pretende realizar na pesquisa em pauta. A coleta de dados também pode envolver algum tipo de processo de entrevista estruturada, além do questionário contendo itens específicos que pedem aos entrevistados que selecionem algo em um número fixo de opções. (HAIR Jr. et al., 2005, p. 87)

Nesta pesquisa, sobretudo devido à disponibilidade e a quantidade de sujeitos da população, os gestores de escolas no universo considerado, foi utilizada uma amostragem para a coleta de dados. Segundo Cooper e Schindler (2003, p. 150), “a ideia b|sica de amostragem é que, ao selecionar alguns elementos em uma população, podemos tirar conclusões sobre toda uma população".

0 tipo de amostra adequado \{ pesquisa foi a amostragem não probabilística. "Aquela em que a seleção dos elementos da população para compor a amostra depende em parte do julgamento do pesquisador ou do entrevistador no campo. Não há nenhuma chance conhecida de que um elemento qualquer da população venha a fazer parte da amostra" (MATTAR, 2001, p. 73). Apesar deste tipo de amostragem oferecer restrições, como qualquer outra, revela-se útil quando o que se pretende é explorar um campo novo e, principalmente, quando se quer conhecer um universo ainda pouco explorado.

Os sujeitos desta investigação são gestores de escolas públicas do estado do Rio de Janeiro (Rede Municipal e Rede Estadual) e gestores de escolas do Serviço Social da Indústria (Rede 
SESI) e do Serviço Nacional de Aprendizagem Industrial (Rede SENAI).

Como principal meio de coleta de dados foi utilizado o método de levantamento estatístico survey. Segundo Hayman (1969, p. 108), a survey pode ser entendida como o conjunto de técnicas de investigação mediante a qual os sujeitos proporcionam informações sobre si mesmos através de um questionário estruturado.

O questionário nesta pesquisa foi formado apenas por perguntas e/ou afirmativas fechadas com a finalidade de identificar as características da amostra trabalhada nas relações indivíduo/trabalho/organização.

Excetuando-se a primeira parte do instrumento de pesquisa, na qual são coletadas as informações sobre o perfil dos respondentes, o questionário foi elaborado basicamente utilizando-se a escala de Likert.

Malhotra (2001) esclarece que, na escala de Likert, para cada resposta atribui-se um valor numérico que, geralmente, vai de 1 a 5 . A análise pode ser feita item por item (análise de perfil) ou então, pode-se calcular um escore total para cada respondente somando-se os itens.

Com o objetivo de processar todas as informações coletadas a partir da aplicação do questionário, foi utilizado o software de domínio público chamado Census and Survey Processing System (CSPro). Embora o CSPro possibilite obter algumas informações estatísticas, ele não se destina a substituir os software de análise estatística mais sofisticados, tais como SAS, SPSS, Stata etc.

Para as análises estatísticas foi utilizado o Statistical Package for the Social Science (SPSS). Foram realizadas análises exploratórias (descritivas) dos dados, a partir da apuração de frequências simples e cruzadas, tanto em termos absolutos quanto em termos percentuais.

\section{ANÁLISE DOS RESULTADOS}

Foram obtidas 151 respostas, sendo 105 dos gestores da Rede SESI/SENAI (5 não responderam) e 46 da rede pública do Estado do Rio de Janeiro (4 não responderam).

No que diz respeito à distribuição de gênero e estado civil, a amostra é formada, majoritariamente, por mulheres $(85,4 \%)$ casadas $(54,3 \%)$. A amostra como um todo apresenta uma idade média de 43,3 anos.

Constatou-se, também, que enquanto na Rede SESI/SENAI, 82,6\% recebem salários superiores a $R \$ 3.000,00$, na Rede Pública esse percentual cai para 54,5. Provavelmente, por este motivo há muitos profissionais que atuam nas duas Redes (estadual e municipal), pois, pelo menos por enquanto, não é possível alterar o piso salarial no estado do Rio de Janeiro (R \$766,00 para 16 horas semanais), tampouco no município (R\$ 917,82). Entretanto, apesar deste piso salarial, a questão da estabilidade é muito considerada, o que leva a maioria a permanecer na Rede Pública.

Com relação ao tempo de trabalho na mesma profissão, verifica-se que apenas $17 \%$ dos gestores da Rede SESI/SENAI têm mais de 20 anos de trabalho na mesma profissão, enquanto na Rede Pública isso ocorre com mais de $74 \%$ dos gestores. Certamente, este resultado corrobora um fato histórico no Brasil: raramente, um brasileiro abandona a atividade pública. 
Como já assinalamos antes, a estabilidade no emprego é um fator relevante.

Com relação ao tempo de trabalho na mesma organização, constata-se no gráfico 6 que 47,2\% dos gestores da Rede SESI/SENAI trabalham nessa organização há até 10 anos, enquanto que na Rede Pública os gestores que tem até 10 anos de trabalho na organização representam somente $20,4 \%$. Na realidade, quase $80 \%$ dos gestores das escolas públicas está na mesma escola a mais de 11 anos, o que também pode indicar uma baixa rotatividade dos profissionais nas escolas da Rede Pública.

Observa-se que cerca de $56 \%$ dos gestores da Rede SESI/SENAI estão há até 5 anos no atual cargo e na Rede Pública esse percentual é de quase 40\%. É interessante notar que apenas 10,2\% dos entrevistados da Rede SESI/SENAI têm mais de 10 anos no cargo, enquanto na Rede Pública esse número chega a quase $35 \%$.

No que diz respeito à satisfação no trabalho, a pesquisa contou com 46 afirmativas relacionadas com a satisfação no trabalho dos gestores escolares. Constatou-se que 93,4\% da Rede Pública e 91,4\% da Rede SESI/SENAI estão satisfeitos e realizados com suas atribuições, isto posto que $95,5 \%$ e $92,4 \%$ dos respondentes, respectivamente, afirmam que no seu trabalho um dos destaques é a possibilidade de aprender coisas novas.

As afirmativas relacionadas ao salário mostram uma diferença significativa entre as respostas dos dois grupos. A saber, os salários são os que resultam em menor satisfação. Na média, apenas 54\% dos gestores do SESI/SENAI mostram-se satisfeitos com seus salários, enquanto na Rede Pública, apenas $27 \%$.

Constata-se que estes resultados corroboram o relatado na revisão de literatura realizada no que diz respeito à motivação salarial. No entanto, é necessário analisar estas respostas no contexto brasileiro onde, somente em 16 de julho de 2008, a Lei 11.738/08 estipulou o piso salarial nacional para os profissionais do magistério público na educação básica, de R \$950,00 para 40 horas de trabalho semanais.

Com relação aos fatores higiênicos, embora 75,2\% dos respondentes da Rede SESI/SENAI estejam satisfeitos (parcialmente ou totalmente) com as condições de iluminação, temperatura, ventilação e ruídos, somente $25,7 \%$ estão totalmente satisfeitos. Para os pesquisados da Rede Pública, estes percentuais ficaram menores: 56,8\% estão satisfeitos parcialmente ou totalmente e apenas 18,3\% estão totalmente satisfeitos.

Quanto questionados sobre a existência de materiais e equipamentos de trabalho em número suficiente e em boas condições na minha instituição, os dois grupos apresentam respostas bastante similares (78,1\% da Rede SESI/SENAI e 80\% da Rede Pública), ou seja, não parece existir uma grande diferença de disposição de materiais e equipamentos de trabalho nas escolas públicas e privadas, pelo menos as da RedeSESI/SENAI.

No que tange à satisfação para com a comunicação institucional, cerca de apenas 11\% dos respondentes das duas Redes afirmam que estão totalmente satisfeitos com a velocidade e clareza com que as informações chegam até eles. Provavelmente, grande parte deste público não está satisfeito com o tempo necessário para tomar conhecimento dos fatos.

Extrapolando os muros da escola, os respondentes afirmam ter orgulho de contar para os outros onde trabalham (80,03\% dos gestores da Rede SESI/SENAI e 95,6\% dos gestores da Rede Pública), pois acreditam que suas escolas têm uma boa imagem junto ao público em 
geral (69,9\% dos gestores da Rede SESI/SENAI e 79,5\% dos gestores da Rede Pública). É importante considerar que o grupo dos gestores públicos municipais é formado por dirigentes de escolas bem avaliadas em sua comunidade e que ocupam posição de destaque entre as escolas públicas do estado. Logo, não é de se estranhar que estes tenham uma percepção clara de como a sua escola é vista pela comunidade.

Além disso, a afirmativa "acredito que a minha instituição contribui para o desenvolvimento social da comunidade onde est| inserida" obteve uma elevada satisfação (parcialmente ou totalmente) nos dois grupos de gestores: 86,7\% para os respondentes da Rede SESI/SENAI e 97,7\% para os da Rede Pública. Destacando-se que apenas 45,7\% dos gestores da Rede SESI/SENAI estão totalmente satisfeitos. Já na Rede Pública, 64,4\% dos gestores estão totalmente satisfeitos.

A satisfação mostrada com a imagem da organização na sociedade não apresenta correspondência com o nível de satisfação para com o empenho da organização em equilibrar as necessidades organizacionais com as necessidades pessoais dos gestores.

Apesar dos níveis de satisfação elevados na Rede Pública, vale ressaltar que somente 6,7\% dos respondentes afirmam estar totalmente satisfeitos com o horário de trabalho e apenas $11,6 \%$ acreditam que a carga de trabalho é adequada. Ao contrário dos gestores da Rede SESI/SENAI que, apesar de acreditarem que não há equilíbrio entre as demandas organizacionais e sua vida pessoal, cerca de 30\% afirmam que estão totalmente satisfeitos com seu horário de trabalho. No entanto, apenas 14,4\% desses gestores estão totalmente satisfeitos com a carga de trabalho.

Embora os gestores das duas Redes acreditem que a organização ainda tem muito a melhorar no que diz respeito a equilibrar suas demandas com as necessidades dos seus dirigentes, $o$ clima organizacional é muito favorável.

O que se observa é que, embora exista um clima de camaradagem nas equipes de trabalho (75,2\% dos gestores do SESI/SENAI e 75,6\% da Rede Pública afirmam ter um bom relacionamento com os colegas), o mesmo não se repete quando considerada a organização como um todo, pois, em média, apenas $40 \%$ dos respondentes acreditam que há um clima de camaradagem nas organizações como um todo.

Constata-se também, apesar do grau de profissionalismo percebido nos relacionamentos, que o nível de satisfação para com as possibilidades de discordância, pelo menos para com os superiores, não é muito adequada, pois apenas cerca de $35 \%$ dos respondentes das duas Redes estão satisfeitos com este fator. 0 fato de trabalhar em uma organização pública, na qual, pelo menos na cultura brasileira, difunde-se a estabilidade e a quase impossibilidade de remover o sujeito do emprego, ainda assim, os colaboradores não se sentem à vontade para discordar dos seus superiores.

As variáveis relativas ao reconhecimento do trabalho também colaboram para com a satisfação com o clima organizacional. 94,4\% dos gestores do SESI/SENAI e 91,1\% da Rede Pública acreditam que seu trabalho é reconhecido pela comunidade onde está inserida sua escola; o que os deixa profundamente satisfeitos.

Enquanto o maior percentual de satisfação dos gestores da Rede SESI/SENAI está relacionado com o reconhecimento que seus subordinados têm de seu trabalho $(57,7 \%), 66,7 \%$ dos 
gestores da Rede Pública têm a percepção mais elevada com relação ao reconhecimento de seus colegas. Na Rede Pública, a afirmativa que obteve o menor percentual de totalmente satisfeito dentre essas cinco afirmativas foi a relacionada com o reconhecimento dos usuários dos serviços prestados pela instituição $(44,4 \%)$.

Observa-se, também, que, de maneira geral, os dois grupos pesquisados têm uma percepção bastante elevada (a partir de 60,0\%) de satisfação para com as possibilidades de crescimento e realização no trabalho que executam. Para 94,3\% dos gestores do SESI/SENAI e 95,6\% da Rede Pública o trabalho proporciona prazer. Do mesmo modo, 93,4\% dos gestores do SESI/SENAIe 97,7\% da Rede Pública afirmam que seu trabalho os realiza.

Entretanto, para os respondentes da Rede SESI/SENAI, a possibilidade de crescimento pessoal $(70,9 \%)$ e de crescimento profissional $(69,5 \%)$ foram as afirmativas com os maiores percentuais obtidos na opção "totalmente satisfeitos". Na escola pública o maior cargo é o de direção o que pode justificar as respostas dos gestores da Rede Pública serem menores nas afirmativas de crescimento profissional e pessoal. Por outro lado, dentro da instituição privada, no caso a Rede SESI/SENAI há outras possibilidades de cargos, pois a escola é uma das organizações da Rede, sendo que o colaborador pode, inclusive, buscar outros cargos fora da escola, dentro da própria instituição, o que pode explicar a valorização das afirmativas de crescimento pessoal e profissional desses gestores.

Resumidamente, observou-se que as variáveis que contribuem para o alto nível de satisfação com o trabalho percebido na Rede SESI/SENAI são: ambiente de trabalho limpo e organizado; conhecimento do que fazer para atingir os objetivos da instituição e os impactos causados pelo trabalho do gestor na obtenção destes objetivos; o prazer que o trabalho proporciona; e, que a experiência profissional permitiu desenvolver habilidades para o desempenho do cargo de gestor. Para os respondentes da Rede Pública, além do conhecimento dos impactos causados pelo trabalho do gestor no alcance dos objetivos de sua organização, o orgulho de contar aos outros onde trabalha e o clima de camaradagem e o trabalho e equipe na instituição tiveram altos índices de satisfação.

Do mesmo modo, as variáveis que apresentam os menores índices de satisfação com o trabalho percebido na Rede SESI/SENAI foram os relacionados ao salário, comunicação interna na instituição e estabilidade no emprego. Para os gestores da Rede Pública as maiores insatisfações relacionam-se com o salário e à carga de trabalho.

\section{CONSIDERAÇÕES FINAIS}

Nesta dissertação foram abordados dois temas relevantes na vida contemporânea dos indivíduos, sentido do trabalho e satisfação no trabalho, analisados junto a um grupo de gestores educacionais.

As principais perguntas desta pesquisa buscavam saber qual o sentido do trabalho para os gestores educacionais, se há sentido no trabalho na escola e na responsabilidade em geri-la e quais os fatores que afetam a satisfação destes indivíduos no exercício de suas funções gerenciais.

Ao longo do desenvolvimento desta pesquisa foi possível obter uma série de informações que contribuirão para aumentar o conhecimento acadêmico dos elementos abordados na mesma.

Com relação à satisfação no trabalho, observa-se que os fatores que mais influenciam na 
satisfação dos pesquisados são a realização, o reconhecimento, a remuneração e as condições físicas de trabalho, que foram obtidos como resultado da análise fatorial de forma muito clara.

É oportuno salientar que a teoria dos dois fatores de Herzberg (1962) busca explicar o comportamento das pessoas em situação de trabalho. Para esse autor há os fatores motivacionais - que quando são ótimos, provocam a satisfação nas pessoas e quando são ruins ou precários, evitam a satisfação - e os fatores higiênicos que apenas evitam a insatisfação, ou seja, não geram satisfação. A realização e o reconhecimento fazem parte dos fatores motivacionais enquanto que a remuneração e as condições físicas de trabalho são considerados fatores higiênicos.

Os gestores educacionais apresentaram um nível de satisfação bastante elevado quanto à realização com o trabalho, expressa, principalmente, nas afirmativas relacionadas com: o orgulho de contar aos outros onde trabalha; o crescimento pessoal e profissional; o equilíbrio entre a capacidade profissional do gestor e o cargo que ele ocupa; e, a possibilidade de variação das atividades executadas.

Da mesma forma, observou-se que o reconhecimento, por colegas, subordinados, superiores e usuários dos serviços prestados, do trabalho realizado pelo gestor também apresentou um nível de satisfação bastante elevado.

Há que se destacar que entre os dois grupos pesquisados houve uma diferença significativa entre os salários percebidos. De acordo com as comparações realizadas ao longo desta dissertação, os salários dos gestores educacionais da Rede Pública, em geral, são inferiores aos salários dos gestores da Rede SESI/SENAI.

Em relação às condições físicas de trabalho dos gestores educacionais, os dois grupos estão bem satisfeitos e destacam, especialmente, a limpeza e organização do ambiente de trabalho, os materiais e equipamentos necessários para o bom funcionamento da organização e as condições de luminosidade, temperatura e ruído. Este resultado não deixa de ser, de certa forma, surpreendente, uma vez que há uma percepção que a Rede Pública não dispõe de condições adequadas para a realização de suas atividades. Porém, não se pode perder de vista que os gestores educacionais da Rede Pública, pesquisados nesta dissertação, formam uma elite dentro deste segmento, pois são os dirigentes das escolas municipais que tiveram o melhor desempenho no estado segundo as avaliações nacionais e do índice FIRJAN, além de contar com os gestores educacionais estaduais indicadas pela Secretaria Estadual de Educação.

Nas relações de correlação, esta pesquisa encontrou poucos relacionamentos com intensidade entre o sentido do trabalho e a satisfação no trabalho dos gestores educacionais. Entretanto, as correlações existem e devem ser objeto de futuros estudos, com a intenção de aprofundar mais o conhecimento sobre elas, e também buscar compreender como o sentido do trabalho para os gestores educacionais pode contribuir mais com a sua satisfação e vice e versa. Uma das alternativas é aplicar o questionário em um número maior de gestores escolares com o objetivo de aumentar a quantidade de dados sobre os mesmos construtos e afirmativas. Além disso, a partir de outras análises estatísticas, será possível analisar as afirmativas utilizadas neste questionário e fazer alterações no sentido de adequá-las a futuras aplicações junto a um público alvo com características semelhantes à desta pesquisa.

Corroborando outras pesquisas junto a profissionais de educação, há evidências nesta 
pesquisa de que as pessoas que escolhem trabalhar na área educacional têm efetivamente o desejo intrínseco de prestação de um serviço que contribua mais objetivamente com a sociedade, uma vez que, de acordo com Drucker (2002), a educação é percebida como o principal vetor de desenvolvimento do indivíduo e, por conseguinte, na formação de uma sociedade mais justa e igualitária.

\section{REFERÊNCIAS}

ARCHER, E. R. O mito da motivação. In: BERGAMINI, C. W., CODA, R. Psicodinâmica da vida organizacional: motivação e liderança. São Paulo: Livraria Pioneira Editora, 1990, p.3-24

BERGAMINI, C. W. A dinâmica da motivação. In: BERGAMINI, C. W., CODA, R. Psicodinâmica da vida organizacional: motivação e liderança. São Paulo: Livraria Pioneira Editora, 1990a, p. $45-63$

BERGAMINI, C. W. Características motivacionais nas empresas brasileiras. RAE, out./dez. 1990b. São Paulo, 30(4) 41-52

BOWDITCH, J. L. e BUONO, A. F. Elementos do comportamento organizacional. São Paulo: Pioneira, 1992.

CODA, R. A relação entre motivação, satisfação no trabalho e administração de RH. In: BERGAMINI, C. W., CODA, R. Psicodinâmica da vida organizacional: motivação e liderança. São Paulo: Livraria Pioneira Editora, 1990, p. 87-91.

COOPER, D. R. e SCHINDLER, P. S. Métodos de pesquisa em Administração. Porto Alegre: Bookman, 2003.

CROSSMAN, A. e HARRIS, P. Job Satisfaction of Secondary School Teachers. Educational Management Administration Leadership, Jan., 2006, v. 34, p. 29-46.

DE COOMAN, R. et al. Graduate teacher motivation for choosing a job in education. International Journal for Educational Vocational Guidance, 2007, v. 7, n. 2, p. 123136

DRUCKER, P. 0 melhor de Peter Drucker: o homem. São Paulo: Editora Nobel, 2002.

EDVINSSON, L. e MALONE, M.S. Capital Intelectual: descobrindo o valor real de sua empresa pela identificação de seus valores internos. São Paulo: Makron Books, 1998.

HAIR JR., J. F. et al. Fundamentos de métodos de pesquisa em administração. Porto Alegre: Bookman, 2005

HAMPTON, David R. Conceitos de comportamentos na administração. São Paulo: EPU, 1973.

HANDY, C. B. Como compreender as organizações. Rio de Janeiro: Zahar, 1978.

HERZBERG, F.; MAUSNER, B. e SNYDERMAN, B. B. The motivation to work. 2. ed. New York: John Wiley \& Sons, Inc., 1962.

HERZBERG, F. O conceito da higiene como motivação e os problemas do potencial humano de trabalho. In: HAMPTON, D. Conceitos de comportamento na administração. São Paulo: EPU, 1973 p. 53-62

HERZBERG, F. Work and the nature of man. London: Staples Press, 1968.

HICKSON, D. J. e Pugh, D. S. Os teóricos das organizações. Rio de Janeiro: Qualitymark, 2004. 
KARPINSKI, D. e STEFANO, S. R. Qualidade de vida no trabalho e satisfação um estudo de caso no setor atacadista de beneficiamento de cereais. Revista Eletrônica Lato Sensu, n.1, março de 2008. Acesso em: 6 nov. 2010. Disponível em: <http://web03.unicentro.br/especializacao/Revista_Pos/P\%C3\%A1ginas/3\%20Edi\%C3 \%A7\%C3\%A3o/Aplicadas/PDF/31-Ed3_CS-QualidadeTr.pdf>.

KOUZES, J. M. e POSNER, B. Z. 0 desafio da liderança. Rio de Janeiro: Campus, 1991.

MAESTRO FILHO, A. e DIAS, D. V. Práticas inovadoras de treinamento e satisfação no trabalho: um modelo relacional de estudo com profissionais de organizações mineiras. I Encontro de Pessoas e Relações de Trabalho, Natal (RN), 13 a 15, jun. 2007.

MALHOTRA, N. Pesquisa de marketing: uma orientação aplicada. Porto Alegre: Bookman, 2001.

MASLOW, A. H. Introdução a psicologia do ser. Rio de Janeiro: Eldorado, 1966.

MASLOW, A. H. Motivation and personality. New York: Harper \& Roe Publishers, 1970.

MATTAR, F. N. Pesquisa de marketing. São Paulo, Atlas, 2001.

MAYO, E. The human problems of on industrial civilization. T. N. Whitehead, The industrial worker. Cambrigde: Mass., Harvard University Press, 1938.

MCGREGOR, D. O lado humano da empresa. In: HAMPTON, D. Conceitos de comportamento na administração. São Paulo: EPU, 1973, p. 7-22.

MCGREGOR, D. Os aspectos humanos da empresa. 2. ed. Lisboa: Livraria Classica, 1970.

MONTANA, P. J. e CHARNOV, B. H. Administração. São Paulo: Saraiva, 1998.

REVISTA VEJA RIO. Eles se destacaram em 2010. Rio de Janeiro, 17 nov. 2010. Acesso em: 20 nov. 2010. Disponível em: <http://vejabrasil.abril.com.br/rio-dejaneiro/editorial/m2155/eles-se-destacaram-em-2010>.

RIBEIRO, D. Nossa escola é uma calamidade. Rio de Janeiro:Salamandra, 1984.

RODRIGUES, M. V. Qualidade de vida no trabalho: evolução e análise no nível gerencial. Rio de Janeiro: Vozes, 1994.

TIMOSSI, L. S. et al. Análise da qualidade de vida no trabalho de colaboradores com diferentes níveis de instrução através de uma análise de correlações. Produção, 2010, vol.20, n.3, pp. 471-480. Acesso em: 06 nov. 2010. Disponível em <http://www.scielo.br/pdf/prod/v20n3/AOP_200901009.pdf>.

TRIPODI, Tony et al. Análise da pesquisa social. Rio de Janeiro: Francisco Alves, 1975.

ULRICH, D. Recursos Humanos Estratégicos: novas perspectivas para os profissionais de RH. São Paulo: Editora Futura, 2000.

URWICK, Lyndall. F. The elements of administration. New York: Harper and Bros, 1943.

WERTHER Jr., Wiilliam B. DAVIS, Keith. Administração de pessoal e Recursos Humanos. São Paulo: McGraw-Hill do Brasil, 1983. 